\title{
A disfunção cognitiva nas doenças neurodegenerativas
}

\author{
Susana A. Gonçalves*, Tiago Fleming Outeiro**
}

\section{Resumo}

As doenças neurodegenerativas são neuropatias que incluem as doenças de Parkinson (DP), de Alzheimer (DA) e de Hungtington, assim como a esclerose lateral amiotrófica e demências fronto-temporais. Podendo variar na sua patofisiologia, estas doenças estão associadas ao envelhecimento geral da população, e à presença comum de formas proteicas misfolded e agregadas no cérebro dos indivíduos afectados. A relação entre o misfolding de determinadas proteínas e a evolução para uma patologia cerebral não é totalmente compreendida. Em alguns casos, a deposição de agregados proteicos parece perturbar fisicamente o funcionamento de alguns grupos de células específicos e estender-se posteriormente para os respectivos tecidos e orgãos onde estão localizadas. Em outros casos, a ausência de proteína funcional, devido ao seu recrutamento para os agregados acumulados, resulta na falha de processos celulares cruciais. A médio e longo prazo e dependendo da zona cerebral que é primeiramente afectada, défices cognitivos podem evoluir em demência, que pode incluir perdas de memória pontuais ou até perda de identidade. Aqui, revemos os mecanismos celulares que despoletam DP e DA, relacionando os mesmos com estados de disfunção cognitiva típicos que progressivamente podem acompanhar estas doenças do envelhecimento.

Palavras-chave: Envelhecimento humano. Doenças neurodegenerativas. Disfunção cognitiva. Proteína funcional.

\section{Introdução: misfolding proteico e o seu papel em doenças neurodegenerativas}

No último século, a esperança média de vida aumentou em média 30 anos nas regiões desenvolvidas do mundo. Esta é uma das conquistas mais remarcadas da história da humanidade, mas representa também um dos maiores desafios no que se refere a manter a qualidade de vida na terceira idade (NICCOLI; PARTRIDGE, 2012).

* Doutoranda em Ciências Biomédicas, especialidade de Neurociências pela Faculdade de Medicina da Universidade de Lisboa. Pesquisadora do Instituto de Medicina Molecular - IMM, Unidade de Neurociência Molecular e Celular/Faculdade de Medicina da Universidade de Lisboa, Portugal. E-mail: susana.goncalves@ fcm.unl.pt

** Doutor pelo Whitehead Institute for Biomedical Research, MIT, EUA. Pós-Doutor pelo Departamento de Neurologia do Hospital Geral de Massachusetts, Harvard Medical School. Pesquisador do Cedoc, Nova Medical School, Faculdade de Ciências Médicas, Universidade Nova de Lisboa, Portugal. Department of Neurodegeneration and Restorative Research, University Medical Center Göttingen, Göttingen, Germany e Max Planck Institute for Experimental Medicine, Göttingen, German. E-mail: touteiro@gmail.com

$\rightarrow$ http://dx.doi.org/10.5335/rbceh.v12i3.6007

Recebido em: 03/11/2015. Aceito em 30/11/2015. 
As doenças neurodegenerativas são neuropatias relacionadas com alterações na conformação nativa das proteínas que incluem as doenças de Parkinson (DP), de Alzheimer (DA) e de Hungtington (HD), assim como a esclerose lateral amiotrófica e demências fronto-temporais (CHERRA; CHU, 2008). Podendo variar na sua patofisiologia, estas doenças estão associadas ao envelhecimento geral da população, e à presença de formas proteicas misfolded e agregadas no cérebro dos indivíduos afectados.

A relação entre o misfolding de determinadas proteínas e a evolução para uma patologia cerebral não é totalmente compreendida. As consequências gerais da alteração da função de uma proteína neuronal são a formação de deposições proteicas no interior ou no exterior do neurónio, levando à perturbação dos mecanismos de síntese e transporte de moléculas, dos mecanismos de degradação e de controlo de qualidade da célula e a uma perturbação na comunicação interneuronal. No seu conjunto, estas doenças designam-se também de doenças conformacionais, e representam grandes desafios para a Medicina actual, que tenta encontrar terapias apropriadas que minimizem o impacto da deposição de agregados proteicos nos neurónios.

Em alguns casos, a deposição de agregados proteicos parece perturbar fisicamente o funcionamento de alguns grupos de células específicos e estender-se posteriormente para os respectivos tecidos e regiões adjacentes. Em outros casos, a ausência de proteína funcional, devido ao seu recrutamento para os agregados acumulados, resulta na falha de processos celulares cruciais (WIL-
LIAMS; PAULSON 2008; YOSHIIKE et al., 2008). Contudo, em DA e DP, à semelhança do que acontecem com as doenças degenerativas, os sintomas parecem surgir devido ao ganho de função tóxica que resulta do processo de agregação proteica. Esta começa por uma organização mais simples em oligómeros, evoluíndo posteriormente em protofibrilhas, fibrilhas amilóides ou outros intermediários (CAUGHEY, 2001; ROSS; PICKART, 2004) (Figura 1).

Figura 1 -Representação esquemática dos processos de folding / unfolding / misfolding

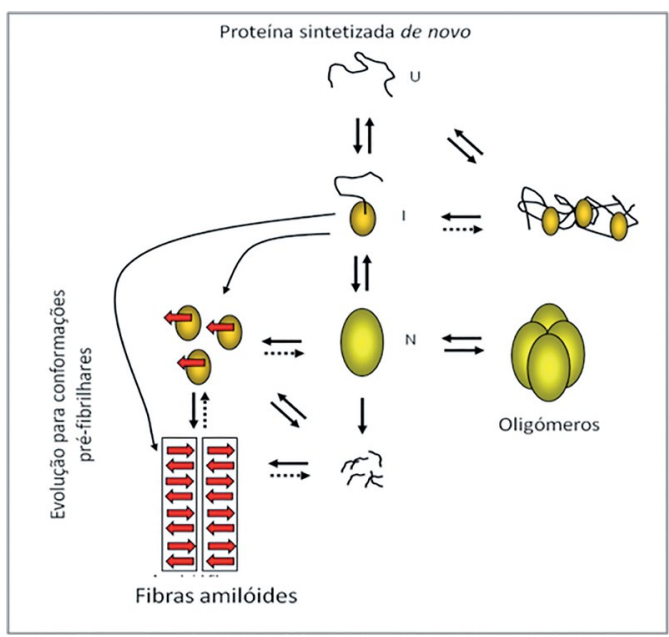

Uma vez sintetizadas de novo, as proteínas têm de se adaptar às várias condições ambientais que encontram, tendo a necessidade de alterarem a sua conformação. Nessas circunstâncias podem ser adquiridas conformações propícias à acumulação de espécies proteicas, o que pode levar a citotoxicidade. U: unfolded; I: intermediário; $\mathrm{N}$ : nativa.

Fonte: figura gentilmente cedida pelo Prof. Dr. Tiago Fleming Outeiro.

Segundo a hipótese amilóide, desenvolvida originalmente para a DA, a agregação de proteínas numa estrutura fibrilhar está relacionada com interacções proteicas aberrantes que culminam 
na disfunção neuronal e, em última instância em neurodegeneração (BRODY et al., 2008; KORCZYN, 2008). Especificamente, certas proteínas com uma determinada função neuronal, devido a determinadas razões, algumas conhecidas, outras não, perdem ou alteram a sua função inicial, muitas vezes tornando-se tóxicas para o neurónio, levando à formação de lixo celular sob a forma de acumulações insolúveis designadas de agregados, que ao longo do tempo levam à disfunção e posteriormente à morte neuronal. Apesar de a célula possuir mecanismos de defesa e de reparação que o próprio organismo acciona contra essas proteínas tóxicas, as doenças neurodegenerativas surgem quando já nenhum mecanismo de defesa funciona na sua plenitude, e quando já há saturação dessas proteínas disfuncionais nos neurónios. Assim, no contexto das doenças neurodegenerativas, a hipótese amilóide, postula que as proteínas podem ser convertidas, sob certas circunstâncias, em estruturas não nativas com propensão para a instabilidade.

Essa instabilidade resulta de: 1) as proteínas falharem em adoptar uma estrutura funcional e essa falha não ser detectada pelos mecanismos de qualidade de controlo da célula, como os chaperones e os sistemas de degradação; 2) nesta fase, essas proteínas começam a ter entre si interações aberrantes que formam estruturas amilóides insolúveis, criando uma cascata de agregação e de lixo proteico que dificulta os processos biológicos da célula, podendo levar, a médio ou longo prazo, à morte neuronal. As mutações genéticas e modificações pos- -traducionais e o próprio envelhecimento aumentam a propensão à agregação de proteínas que acontece em DP, DA, HD, e ataxia cerebral. Contudo, os mecanismos moleculares envolvidos em toda esta cascata são ainda pouco conhecidos para cada uma das doenças (AULUCK; CARAVEO; LINDQUIST, 2010).

Apesar de existirem diversas vias que levam à neurodegeneração, o resultado geral é a perda de função parcial do sistema nervoso central e o declínio dos processos cognitivos e/ou motores. Assim, conhecer a base desse declínio cognitivo é pertinente para o desenvolvimento de futuras terapias.

\section{Disfunção cognitiva induzida por stress}

A memória é o processo pelo qual a informação é codificada, armazenada e utilizada quando necessário, em resposta a estimulos externos. Existem múltiplas estruturas do cérebro envolvidas no processo de memória, ora estruturas organizadas de linguagem, de visão, de emoção e de processamento da informação vinda do exterior.

A memória pode ser sensorial e a curto prazo, e tem uma capacidade e duração limitada, ou podemos ter memória durante a vida toda de determinada informação. Diferentes zonas do cérebro estao envolvidas no processo de memória, como o hipocampus, amígdala, estriado, entre outras regiões.

A capacidade para gerir e actuar perante estimulos externos é critica no dia-a-dia e baseia-se na memória imediata. Estes processos dependem da integridade estrutural e funcional do cortex 
pré-frontal. Esta é uma região do cérebro que gere as emoções e comportamentos e é rica em projecções sucborticais vindas do hipotálamo, amígdala e o tronco do cérebro (MIYAMOTO; OSADA, 2014).

\section{Stress e Memória}

$\mathrm{O}$ stress interfere na capacidade de um indivíduo produzir memória e de utilizar a já adquirida. Sob stress, o corpo reage secretando hormonas específicas no sangue. Se secretadas continuamente e em excesso, podem causar danos no hipocampos, cortex prefrontal e amígdala, e consequentemente na memória. $\mathrm{O}$ cortisol é a hormona mais libertada sob stress, e vai preparar o sistema nervoso periférico para determinada acção, aumentando os níveis de açúcar no sangue e suprimindo a imunidade para que haja uma resposta adequada e rápida ao stress. As catecolaminas despotelam uma resposta emocional ao stress, como seja a sensação de medo.

As catecolaminas derivam do aminoácido tirosina, sendo as mais abundantes a dopamina, a adrenalina e a noradrenalina. A dopamina é um neurotransmissor produzido nos corpos celulares neuronais da substantia nigra e da area tegmental ventral. No cérebro, a dopamina funciona como um neurotransmissor, e tem várias funções, entre elas o controlo da libertação de várias hormonas no cérebro, o controle motor, sendo importante também para o comportamento de recompensa. A noradrenalina actua no sistema nervoso central e a adrenalina no sistema nervoso periferico. Ambas preparam o corpo para atividade fisica, aumentam a pulsação cardíaca, a pressão sanguínea, entre outros efeitos.

O stress agudo contínuo pode levar à desregulação daqueles efeitos, o que resulta em decisões e atos inadequados ou exagerados perante determinada situação. A ação prolongada de catecolaminas pode afetar o humor, criando um feedback negativo entre emoções e fisiologia. Também pode levar a inflamações crónicas, distúrbios do sono, à falha da capacidade de reacção, e a alterações cardiovasculares e metabólicas, sendo que a qualidade de vida fica grandemente afetada. A nível crónico, o stress pode levar ao confinamento em si mesmo, desconfiança, a perturbações mentais e isolamento social (MCEWEN, 2013).

\section{Défice cognitivo leve e Demência}

Ao longo do envelhecimento, pode haver declínio de memória e das capacidades cognitivas, mas continua a ser extremamente difícil perceber se esse declínio continuará estável e não perturbará a qualidade de vida, ou se progriderá para uma demência severa.

O Défice cognitivo leve (ou DCL, do inglês mild cognitive impairment), e demência, não são doenças específicas, mas antes, representam uma condição severa de perda de conhecimento que é causa ou consequência de certa doença.

Assim, o DCL é um estado que não interfere com as tarefas do dia-a-dia, sendo um estado pré-demência. Posteriormente, a demência pode surgir, primeiro de maneira leve ou moderada e pode culminar num estado severo de perda de autonomia, de noção do contexto e da própria identidade. 
A demência implica por um lado perda de memória e por outra uma perturbação em pelo menos uma área cognitiva: linguagem, capacidade de resolução de problemas, atenção, percepção, ou capacidade de julgamento.

$\mathrm{AD}$ e $\mathrm{PD}$ são doenças que podem levar défice cognitivo a evoluir em demência, acelerando o processo (KNOPMAN; PETERSEN, 2014).

Dependendo da área do cérebro mais afectada, existem vários tipos de demência. A primeira demência a ser descrita foi por Alzheimer (1907). Envolve perda de memória, desorientação, dificuldade em falar, perda de identidade. A doença de Parkinson pode culminar numa demência semelhante à de Alzheimer apesar dos primeiros sintomas da doença serem predominantemente motores. Outras doenças neurodegenerativas existem que podem culminar em demência em certo ponto do seu desenvolvimento: demência com corpos de Lewi, HD, Creutzfelt-Jakob, entre outras (BOERSMA et al., 2014).

\section{Doença de Parkinson}

Descrita pela primeira vez por James Parkinson (1817), a DP é uma doença caracterizada por tremores em repouso, rigidez muscular, perda de destreza nos movimentos e depressão (LUCKING; BRICE, 2000).

A maioria dos casos de DP são esporádicos, mas conhecem-se já alguns genes associados às formas familiares da doença (WALES, 2013). A nível patológico, a doença é caracterizada por uma perda geral de neurónios dopaminérgicos na substantia nigra (Figura 2), e pela formação de inclusões proteicas citoplasmáticas, conhecidas por corpos de Lewy (CL), nos neurónios remanescentes. É típico surgirem também agregações fibrilhares, designadas por neuritos de Lewy (Figura 3). O principal constituinte destas acumulações proteicas anormais é a alfa-sinucleína ( $\alpha$ syn) (LUCKING; BRICE, 2000).

Figura 2 - Patofisiologia da DP

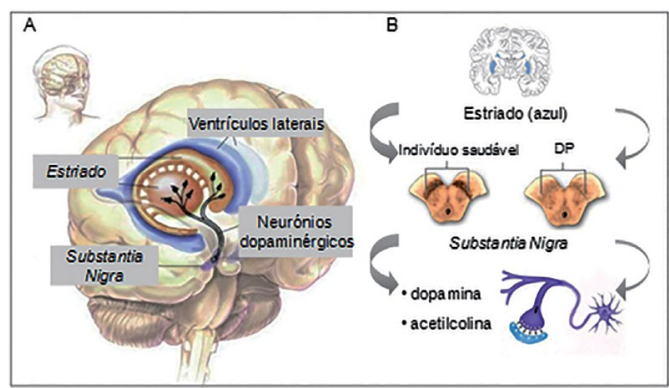

A) localização do estriado no cérebro; B) comparação esquemática entre a substantia nigra de um indivíduo saudável e de um doente com Parkinson. Neste, a perda de neurónios dopaminérgicos (pigmentados), responsáveis pela produção de neurotransmissores (dopamina e acetilcolina), faz com que haja menor libertação daqueles para o estriado. Posteriormente, isto culmina numa degeneração geral do cérebro e do sistema nervoso, que leva aos sintomas típicos de DP.

Fonte: adaptado de http://homepages.inf.ed.ac.uk/anaru/ research/anatomy (A), www.beverlyhillsneurology. com, www.hcnr.med.harvard.edu (B).

Apesar de a função desta proteína pré-sináptica ser pouco clara, existem várias implicações fisiológicas propostas para a mesma, sendo uma das mais relevantes o seu envolvimento na plasticidade sináptica, na medida em que ratinhos knockout para a asyn possuem défices de produção de vesículas celulares (CABIN et al., 2002). Além disso, a asyn parece actuar como um regulador negativo da neurotransmissão de dopamina (ABELIOVICH et al., 2000). Outros estudos 
sugerem o envolvimento da asyn no recrutamento de complexos necessários para o transporte retículo endoplasmático-complexo de Golgi e para a fusão vesicular com a membrana plasmática (CHANDRA, 2005; COOPER, 2006; GITLER, 2008; CHUTNA, 2014; GONCALVES, 2016). Por outro lado, a disfunção de $\alpha$ syn está associada a défices funcionais do proteossoma (COOPER, 2006), aumento da produção de espécies de oxigénio reactivas e disfunção mitocondrial (OUTEIRO; LINDQUIST, 2003; FASANO; LOPIANO, 2008).

A duplicação e triplicação do gene da asyn (SNCA) está associada a um aumento da severidade da DP em casos familiares. Além disso, a idade média de aparecimento é consideravelmente reduzida nestes casos de DP familiar (SINGLETON, 2003), passando dos 65 anos para os 40-50 anos. Por outro lado, estão descritas seis mutações génicas de SNCA (A53T, A30P, E46K, H50Q, G51D e A53E), também associadas a outras formas familiares da doença (KRUGER, 1998; MEZEY, 1998; ZARRANZ, 2004; APPEL-CRESSWELL, 2013; PROUKAKIS, 2013; FARES, 2014; PASANEN, 2014).

Figura 3 -Inclusões proteicas características em PD

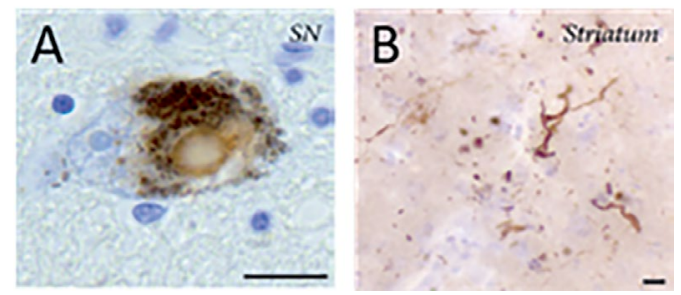

A) corpo de Lewy; B) Neurito de Lewy. Escala: $25 \mu \mathrm{m}$. Fonte: adaptado de Mccann, (2014).
Pensa-se que a acumulação de $\alpha$ syn sob uma forma misfolded é um passo precoce na patogénese de ambas as formas esporádica e familiar de DP (SINGLETON, 2003). O misfolding de asyn assume várias conformações, variando desde monómeros, oligómeros, protofibrilhas e fibrilhas, sendo que as formas mais complexas são as inclusões (GONCALVES; MATOS; OUTEIRO, 2010). Contudo, as formas diméricas/oligoméricas, precursoras das inclusões proteicas características de $\alpha$ syn, parecem ser as espécies mais tóxicas (DANZER, 2007; OUTEIRO, 2008).

\section{Défice cognitivo em Doença de Parkinson}

O défice cognitivo é uma complicação não motora na doença de Parkinson que está associada tanto a uma incapacidade significativa por parte do paciente como a um fardo para os cuidadores. $30 \%$ dos casos de PD incluem demência e $20 \%$ já a possuem no momento de diagnóstico. Mas sabe-se muito pouco acerca dos mecanismos que despoletam este défice cognitivo, principalmente devido à heterogeneidade do fenómeno, ou seja, podem ser défices graves ou não, que aparecem cedo ou tarde na doença.

Uma maneira de tentar classificar o grau de défice cognitivo é testanto grau de atenção do paciente. Existem testes à atenção simples do doente, como repetir uma sucessão de números pela mesma ordem em que foram apresentados, ou contagens regressivas. Existem também testes à capacidade de raciocínio do paciente, que incluem aritmetica mental, jogos e desafios. 
Como sugerido primeiro por Braak et al. (2003) e depois por outros, a doença de Parkinson afeta primeiro o bolbo olfactório, depois evolui em modo ascendente pela substantia nigra afectando os neurónios dopaminérgicos, amygdala, e numa fase posterior, o cortex cerebral é atingido. Aqui já os sintomas são notórios e a doença está diagnosticada e em estado avançado, o que pode estar relacionado com o défice cognitivo, já que várias áreas do cérebro são seriamente afectadas (SIEPEL, 2014).

\section{Modulação da Agregação de Alfa-sinucleína como Potencial Terapêutico}

A compreensão dos processos de misfolding, interacções proteicas e agregação da $\square$ syn é essencial para o desenvolvimento de novas estratégias terapêuticas em DP. As estratégias existentes (terapia com levodopa ou estimulação profunda do cérebro) podem ter efeitos secundários severos a longo prazo (FAHN, 2004), ou atenuarem apenas alguns dos sintomas (ARLE, 2008), sendo que se torna cada vez mais necessário um impulso terapêutico nesta área; as terapias actuais tratam os sintomas, mas não tratam nem retardam a degeneração neuronal.

O maior obstáculo para o desenvolvimento de terapias neuroprotectoras é o conhecimento limitado que temos dos eventos moleculares que levam à neurodegeneração (DAUER; PRZEDBORSKI, 2003). No contexto das sinucleinopatias, a inibição da fibrilhação de $\alpha$ syn por efeitos de drogas é aplicável sem se compreender o mecanismo molecular da formação de agregados que leva à neurotoxicidade; as espécies precursoras da acumulação de $\alpha$ syn são as mais tóxicas (OUTEIRO, 2008) e qualquer droga que promova a desagregação das fibrilhas em oligómeros mais simples pode provocar o agravamento da doença por aumento da toxidade celular. Assim, os avanços moleculares terão de ser feitos no sentido de tentar estabilizar a conformação de asyn na célula, ou tentar bloquear completamente a sua tendência para a agregação (UVERSKY, 2007).

Quando estes avanços progredirem, o seguimento dos mesmos será útil para o estudo de outras sinucleinopatias além de DP, como sejam a demência de CL e a atrofia dos sistemas múltiplos.

\section{Doença de Alzheimer}

No que se refere à doença de Alzheimer, é a causa mais comum de demência. Afeta cerca de $7 \%$ de pessoas com mais de 65 anos e mais de $40 \%$ de pessoas com mais de 80 anos. Pensa-se que nos próximos 25 anos o numero de doentes com $\mathrm{AD}$ nos Estados Unidos da América irá triplicar, assim como os custos sociais associados.

A doença pode ter origem esporádica ou pode estar associada a mutações no gene que codifica para a proteina precursora amilóide (PPA) ou nos genes da presenilina 1 e 2. Estas mutações estão associadas a níveis aumentados de peptidos Abeta que formam as fibrilhas aberrantes presentes nos neurónios.

A alteração mais comum nos neurônios é o aparecimento de emaranhados fibrilhares no corpo celular do neurónio 
e nas dendrites. Estes corpos são compostos por algumas isoformas de Tau, uma proteina associada a microtúbulos, sendo que estes fazem parte do esqueleto da célula, suportando-a.

As células afectadas vêem o transporte axonal limitado assim como as funções sinápticas, e por fim, a viabilidade neuronal. Se os neurónios morrem, as conexões sinápticas nas regiões do cérebro criticam para a função cognitiva são postos em causa. Também é muito comum haver uma atrofia física do cérebro. Os doentes apresentam também perda de memória, e alucinações (AREVALORODRIGUEZ, 2014).

\section{Terapia nas Doenças Neurodegenerativas}

Determinar os mecanismos de como o cérebro adquire, armazena e usa memórias é um dos grandes desafios das Neurociências. Mesmo havendo só um conhecimento parcial sobre todo este fenómeno do cognitivo, a investigação de novos alvos terapêuticos para tratar défices cognitivos associados a doenças neurológicas está a progredir.

Primeiro, a cognição é um conceito muito complexo que inclui atenção, memória, processos de execução de determinada tarefa. Os défices cognitivos podem evoluir num só sentido, por exemplo a Atencão em Hiperactividade Associada a Défice de Atenção, ou pode haver um défice global de cognição, como na Esquizofrenia. Como não há uma só via envolvida, existem muitos alvos de drogas em estudo:
1. Existem drogas que aumentam a neurotransmissão, e um bom exemplo são os inibidores de acetilcolinesterase. Estes são químicos que impedem a enzima acetilcolinesterase de exercerem a sua função, ou seja, de degradar a acetilcolina. Assim, esta fica disponível em maiores quantidades e durante mais tempo para exercer a sua função de neurotransmissor. A acetilcolina é um modulador da plasticidade e excitação neuronal e é importante na percepção sensorial quando acordamos ou quando prestamos atenção a algum fenómeno.

2. Outras drogas estimulam ou inibem receptores neuronais. São elas agonistas nicotínicos, que mimetizam a acção da acetilcolina, ou antagonistas de receptores nicotínicos, como o 5-hidroxitriptamina 6 (5-Ht6). Este é um receptor que se liga a serotonina. Esta por sua vez é um neurotransmissor excitatório que contribui para os sentimentos de bem estar e felicidade. O 5-HT6 existe no tubérculo olfactório, cortex cerebral, estriado, hipocampo e cerebelum. O bloqueio deste receptor mostrou correlacionar-se com um aumento da neurotransmissão glutamatérgica e colinérgica. Os antagonistas de 5-HT6 facilitam a libertação de dopamina e noradrelanina no cortex frontal, que como já referido, são importantes na memória executora e a curto prazo. Os antagonistas de 5-HT6 são usados em $\mathrm{AD}$ e outros tipos de dementia. 
A manipulaçao genética das células estaminais (ou do tronco) é outra forma promissora para desenvolver terapias nas doenças do cérebro. Recentes avanços permitem manipular células estaminais humanas in vitro, procedendo-se a modificações genéticas e à diferenciação em subtipos específicos de neurônios. Assim, estes podem ser transplantados no tecido do cérebro com a doença. Já se tenta tratar a disfunção cognitiva em DA, através do transplante de neurónios colinérgicos gerados in vitro. Existem ainda melhoramentos a conseguir na técnica, que nem sempre é eficaz, e não é de todo aplicável quando a neurodegeneração já está espalhada por várias zonas do cérebro. Na ultima década, tem já havido ensaios clínicos em animais, ou por substituição dos neurônios colinérgicos mortos por neurónios diferenciados através de células estaminais, ou pela estimulação da neurogénese no hipocampo, usando secreções neurotróficas de células estaminais. Os resultados passam por melhoramento da memória e aprendizagem, da densidade sináptica e do numero de neurónios. Pensa-se que em 5-10 anos ter-se-á progressos na eficácia dos tratamentos actuais da DA, com células estaminais (QUIK, 2011; CAO, 2014; ROSS; AKIMOV, 2014; RUSSO; FINI; CESARIO, 2014).

\section{Conclusão}

O estudo das interações proteicas num contexto celular é crucial para compreender a dinâmica proteica e a sua modulação pelas alterações ambientais, intra e intercelulares. Além disso, a loca- lização subcelular de muitos complexos proteicos pode ajudar a desvendar as suas funções e mecanismos de ação que culminam na patologia de muitas doenças neurodegenerativas.

As proteínas podem ter estados conformacionais alternativos que podem estar associados a disfunção celular, mas os mecanismos exactos são apenas alusivos. Apesar dos componentes proteicos variarem, a formação de inclusões nas doenças neurodegenerativas partilham vias comuns de formação. Assim, é essencial procurar um melhor entendimento dessas anormalidades ao nível bioquímico e molecular, o que é o impulso para que possa haver o desenvolvimento de novas estratégias para intervenção terapêutica.

\section{Cognitive dysfunction in neurodegenerative diseases}

\section{Abstract}

A common hallmark among several neurodegenerative disorders (NDs) is the accumulation of misfolded proteins. These altered proteins enable aberrant protein-protein interactions, the formation of aggregates, and the disruption of several essential cellular functions. This culminates in the impairment of several essential functions such as intracellular trafficking, protein degradation, and mitochondrial function, eventually leading to cell death. This pathologic hallmarks precede the symptomatic phase that can progress in cognitive impairments and ultimately in dementia. Currently there is no cure for Parkinson's disease or Alzheimer's and most, if not all, currently available therapies are just 
symptomatic. While they improve motor dysfunction and other clinical symptoms, they do not modify disease progression nor prevent disease onset. These therapies include pharmacological modulation of the dopamine system, neurosurgery and physical therapy. Here, we outline how some of the recent molecular and genetic research might be used as the basis for the development of novel therapeutic strategies.

Keywords: Human aging. Neurodegenerative diseases. Cognitive dysfunction. Functional protein.

\section{Referências}

ABELIOVICH, A. Mice lacking alphasynuclein display functional deficits in the nigrostriatal dopamine system. Neuron, v. 25, n. 1, p. 239-252, 2000.

APPEL-CRESSWELL, S. Alpha-synuclein p.H50Q, a novel pathogenic mutation for Parkinson's disease. Movement Disorders, v. 28, n. 6 , p. 811-813, 2013.

AREVALO-RODRIGUEZ, I. Diagnostic tools for alzheimer inverted question marks disease dementia and other dementias: an overview of diagnostic test accuracy (DTA) systematic reviews. BMC Neurology, v. 14, n. $1,2014$.

ARLE, J. Motor cortex stimulation in patients with Parkinson disease: 12-month follow-up in 4 patients. Journal of Neurosurgery, v. 109, n. 1, p. 133-139, 2008.

AULUCK, P. K; CARAVEO, G; LINDQUIST, S. Alpha-Synuclein: membrane interactions and toxicity in Parkinson's disease. Annual Review of Cell and Developmental Biology, v. 26, p. 211-233, 2010.

BOERSMA, P. et al. 2014. The art of successful implementation of psychosocial interventions in residential dementia care: a systematic review of the literature based on the RE-AIM framework. International Psycho- geriatrics: 1-17. Disponível em: <http://www. ncbi.nlm.nih.gov/pubmed/25311630>. Acesso em: 20 mar. 2014.

BRAAK, H. et al. Staging of brain pathology related to sporadic Parkinson's disease. Neurobiology of Aging, v. 24, n. 2, p. 197-211, Mar. 2003.

BRODY, D. L. Amyloid-beta dynamics correlate with neurological status in the injured human brain. Science, v. 321, n. 5893, p. 1221-1224, 2008.

CABIN, D. E. Synaptic vesicle depletion correlates with attenuated synaptic responses to prolonged repetitive stimulation in mice lacking alpha-synuclein. Journal of Neurosurgery, v. 22, n. 20, p. 8797-8807, 2002.

CAO, L. Induced Pluripotent Stem Cells for Disease Modeling and Drug Discovery in Neurodegenerative Diseases. Molecular Neurobiology, v. 52, p. 244-255, 2014.

CAUGHEY, B. Interactions and conversions of prion protein isoforms. Advances in Protein Chemistry and Structural Biology, v. 57, p. 139-169, 2001.

CHANDRA, S. Alpha-synuclein cooperates with CSPalpha in preventing neurodegeneration. Cell, v. 123, n. 3, p. 383-396, 2005.

CHERRA, S. J.3 ${ }^{\text {RD }}$; CHU, C. T. Autophagy in neuroprotection and neurodegeneration: A question of balance. Future Neurology, v. 3, n. 3, p. 309-323, 2008.

CHUTNA, O. The small GTPase Rab11 colocalizes with alpha-synuclein in intracellular inclusions and modulates its aggregation, secretion and toxicity. Human Molecular Genetics, v. 23, n. 25, p. 6732-6745, 2014.

COOPER, A. A. Alpha-synuclein blocks ER-Golgi traffic and Rab1 rescues neuron loss in Parkinson's models. Science, v. 313, n. 5785, p. 324-328, 2006.

DANZER, K. M. Different species of alpha-synuclein oligomers induce calcium influx and seeding. Journal of Neurosurgery, v. 27, n. 34, p. 9220-9232, 2007. 
DAUER, W.; PRZEDBORSKI, S. Parkinson's disease: mechanisms and models. Neuron, v. 39, n. 6 , p. 889-909, 2003.

FAHN, S. Levodopa and the progression of Parkinson's disease. The New England Journal of Medicine, v. 351, n. 24, p. 24982508, 2004.

FARES, M. B. The novel Parkinson's disease linked mutation G51D attenuates in vitro aggregation and membrane binding of alpha-synuclein, and enhances its secretion and nuclear localization in cells. Human Molecular Genetics, v. 23, n. 17, p. 4491-4509, 2014.

FASANO, M.; LOPIANO, L. Alpha-synuclein and Parkinson's disease: a proteomic view. Expert Review of Proteomics, v. 5, n. 2, p. 239-248, 2008.

GITLER, A. D. The Parkinson's disease protein alpha-synuclein disrupts cellular Rab homeostasis. Proceedings of the National Academy of Sciences, v. 105, n. 1, p. 145-150, 2008.

GONCALVES, S. A. shRNA-Based Screen Identifies Endocytic Recycling Pathway Components That Act as Genetic Modifiers of Alpha-Synuclein Aggregation, Secretion and Toxicity. PLoS Genetic, v. 12, n. 4, 2016.

GONCALVES, S. A.; MATOS, J. E.; OUTEIRO, T. F. Zooming into protein oligomerization in neurodegeneration using BiFC. Trends in Biochemical Sciences, v. 35, n. 11, p. 643-651, 2010.

KNOPMAN, D. S.; PETERSEN, R. C. Mild Cognitive Impairment and Mild Dementia: A Clinical Perspective. Mayo Clinic Proceedings, v. 89, n.10, p. 1452-1459, 2014.

KORCZYN, A. D. The amyloid cascade hypothesis. Alzheimers \& Dementia, v. 4, n. 3, p. 176-178, 2008.

KRUGER, R. Ala30Pro mutation in the gene encoding alpha-synuclein in Parkinson's disease. Nature Genetics, v. 18, n. 2, p. 106-108, 1998.
LUCKING, C. B.; BRICE. A. Alpha-synuclein and Parkinson's disease. Cellular and Molecular Life Sciences, v. 57, n. 13, p. 1894-1908, 2000.

MCCANN, H. Alpha-Synucleinopathy phenotypes. Parkinsonism \& Related Disorders, v. 1, p. 62-67, 2014.

MCEWEN, B. S. The Brain on Stress: Toward an Integrative Approach to Brain, Body and Behavior. Perspectives on Psychological Science, v. 8, n. 6, p. 673-675, 2013.

MEZEY, E. Alpha synuclein is present in Lewy bodies in sporadic Parkinson's disease. Molecular Psychiatry, v. 3, n. 6, p. 493-499, 1998.

MIYAMOTO, K. T.; OSADA, Y. AdachiRemapping of memory encoding and retrieval networks: Insights from neuroimaging in primates. Behavioural Brain Research, v. 275 , p. $53-61,2014$.

NICCOLI, T.; PARTRIDGE, L. Ageing as a risk factor for disease. Current Biology, v. 22, n. 7, p. 741-752, 2012.

OUTEIRO, T. F.; LINDQUIST, S. Yeast cells provide insight into alpha-synuclein biology and pathobiology. Science, v. 302, n. 5651, p. 1772-1775, 2003.

OUTEIRO, T. F. Formation of toxic oligomeric alpha-synuclein species in living cells. PLoS One, v. 3, n. 4, p. 1772-1775, 2008.

PASANEN, P. Novel alpha-synuclein mutation A53E associated with atypical multiple system atrophy and Parkinson's disease-type pathology. Neurobiology of Aging, v. 35, n. 9 , p. 2180-2185, 2014.

PROUKAKIS, C. A novel alpha-synuclein missense mutation in Parkinson disease. Neurology, v. 80, n. 11, p. 1062-1064, 2013.

QUIK, M. Targeting nicotinic receptors for Parkinson's disease therapy. CNS \& Neurological Disorders - Drug Targets, v. 10, n. 6, p. 651-658, 2011. 
ROSS, C. A.; AKIMOV, S. S. Human-induced pluripotent stem cells: potential for neurodegenerative diseases. Human Molecular Genetics, v. 23, n. 1, p. 17-26, 2014.

ROSS, C. A.; PICKART, C. M. The ubiquitin-proteasome pathway in Parkinson's disease and other neurodegenerative diseases. Trends in Cell Biology, v. 14, n. 12, p. 703-711, 2004.

RUSSO, P.; FINI, M.; CESARIO, A. Editorial: disease control and active and healthy ageing: new paradigms of therapeutic strategy. Current Pharmaceutical Design, v. 20, n. 38, p. 5919-5920, 2014.

SIEPEL, F. J. Cognitive executive impairment and dopaminergic deficits in de novo Parkinson's disease. Movement Disorders, v. 14, p. 1802-1808, 2014.

SINGLETON, A. B. Alpha-Synuclein locus triplication causes Parkinson's disease. Science, v. 302, n. 5.646, p. 841, 2003.

UVERSKY, V. N. Neuropathology, biochemistry, and biophysics of alpha-synuclein aggregation. Journal of Neurochemistry, v. 103, n. 1, p. 17-37, 2007.

WALES, P. et al. 2013. Disponível em: <http://www.ncbi.nlm.nih.gov/entrez/query. fcgi?cmd=Retrieve \&db=PubMed\&dopt=Cit ation\&list_uids=24270242>.

WILLIAMS, A. J.; PAULSON, H. L. Polyglutamine neurodegeneration: protein misfolding revisited. Trends Neurosci, v. 31, n. 10, p. 521-528, 2008.

YOSHIIKE, Y. et al. Amyloid oligomer conformation in a group of natively folded proteins. PLoS One, v. 3, n. 9, 2008.

ZARRANZ, J. J. The new mutation, E46K, of alpha-synuclein causes Parkinson and Lewy body dementia. Annals of Neurology, v. 55, n. 2, p. 164-173, 2004. 